\title{
Corpos transmasculinos, hormônios e técnicas: reflexões sobre materialidades possíveis*
}

\author{
Érica Renata de Souza**
}

\begin{abstract}
Resumo
Neste artigo, propomo-nos a pensar a partir da noção de uma rede sociotécnica na qual hormônios e outras técnicas se articulam afetando e efetuando os corpos transmasculinos, coproduzindo movimentos e realidades vividas para além do que a Medicina define e entende sobre esses corpos. Vivendo (n)as controvérsias do sistema de saúde, as pessoas trans materializam corpos que não integralmente reconhecidos em sua plenitude humana, política e social.
\end{abstract}

Palauras-chave: Transmasculinidades, Hormônios, Técnica, Materialidade, Redes.

* Recebido em 18 de setembro de 2019, aceito em 06 de julho de 2020.

** Professora de Antropologia no Departamento de Antropologia e Arqueologia e no Programa de Pós-Graduação em Antropologia, Faculdade de Filosofia e Ciências Humanas, Universidade Federal de Minas Gerais (UFMG), Belo Horizonte, MG, Brasil. erica0407@gmail.com / ORCID 0000-0003-2195-8237 
Transmasculine Bodies, Hormones and Techniques: Reflections on Possible Materialities

\begin{abstract}
In this article we reflect on the notion of a sociotechnical network in which hormones and other techniques are articulated, affecting and effectuating transmasculine bodies, co-producing movements and realities lived beyond what medicine defines and understands about these bodies. Experiencing the controversies of the healthcare system, trans people materialize bodies that are not completely recognized in their human, political and social fullness.
\end{abstract}

Keywords: Transmasculinities, Hormones, Technique, Materiality, Networks. 


\section{Introdução}

Esse trabalho pretende apresentar reflexões sobre os resultados de uma pesquisa conduzida por dois anos ao respeito do acesso de homens trans às políticas de saúde em três cidades brasileiras (Belo Horizonte, MG; Campinas, SP; São Paulo, SP). A pesquisa "Transexualidades e saúde no Brasil: entre a invisibilidade e a demanda por políticas públicas para homens trans" foi por mim coordenada, aprovada pelo Comitê de Ética em Pesquisa da Universidade Federal de Minas Gerais e financiada pelo CNPq de 2013 a 2015, tendo contado com a participação de mais dois professores $e$ alunos de graduação, mestrado e doutorado, além da colaboração do então Presidente da Associação Brasileira de Homens Trans $(\mathrm{ABHT})^{1}$, o qual, posteriormente, tornou-se um dos coordenadores da Associação dos Homens Trans e Transmasculinizados (AHTM). Metodologicamente, foram propostas duas fases da pesquisa, além da observação participante $e$ de reuniões preliminares $e$ presenciais com homens trans de $\mathrm{BH}$ e região a fim de subsidiar a elaboração de um questionário. A primeira fase versou sobre o mapeamento de informações e demandas através da internet (redes sociais) considerando o âmbito nacional, com aplicação de questionários online em âmbito regional; a segunda fase foi caracterizada por entrevistas semiestruturadas em âmbito regional (Souza et al., 2015).

1 Professoras/es pesquisadoras/es: Érica Renata de Souza (UFMG, coordenadora do projeto); Marco Aurélio Máximo Prado (UFMG) e Paula Sandrine Machado (UFRGS). Alunas/os da UFMG: Leonel Cardoso dos Santos, Doutorando em Psicologia Social; Rafaela Vasconcelos Freitas, Doutoranda em Psicologia Social; Guilherme da Rocha Campos, Mestrando em Antropologia Social; Lorena Hellen de Oliveira, Mestranda em Antropologia Social; Sofia Gonçalves Repolês, Mestranda em Antropologia Social; Gustavo Ramos Rodrigues, Graduando em Antropologia; Joicinele Alves Pinheiro, Graduanda em Ciências Sociais; Marina Luiza Nunes Diniz, Graduanda em Psicologia; Sara Silveira Soalheiro, Graduanda em Ciências Sociais e Shirlei dos Reis Ribeiro, Graduanda em Antropologia. Colaboradoras/es: Igor Ramon Lopes Monteiro, Mestre em Psicologia Social e Leonardo Tenório, Presidente da Associação Brasileira de Homens Trans até 2014 (data do encerramento de suas atividades). 
Ainda que a pesquisa tenha se apoiado analiticamente na categoria "homens trans", nos termos colocados por Almeida (2012) e também alinhadas/os com a definição do I Encontro Nacional de Homens Trans realizado em 2015 na Universidade de São Paulo, a reflexão aqui em questão se propõe a pensar os corpos transmasculinos. Nesse diálogo entre os estudos de gênero, a teoria queer e a teoria ator rede, entendemos que a noção de transmasculinidades seria mais profícua em termos analíticos, a partir do pressuposto de que a noção de transmasculinidades não tem nenhuma pretensão universalizante (Ávila, 2014; Ávila, 2015) e reconhece a diversidade de vivências e expressões de gênero.

Hoje já é relativamente vasta a produção de pesquisas com referenciais feministas e/ou queer na temática da transmasculinidade, sobretudo nas Ciências Sociais (Ávila, 2014; Oliveira, 2014; Souza e Prado, 2014a; Souza e Prado, 2014b; Ávila, 2015; Oliveira, 2015; Vieira, 2015; Braz \& Souza, 2016; Souza e Braz, 2016; Repolês, 2017; Almeida, 2018; Braz e Souza, 2018; Braz, 2019a; Braz, 2019b; Vieira e Porto, 2019; Braz e Souza, 2020) e foi também nesse bojo que desenvolvemos a pesquisa supracitada.

Esse artigo se apresenta como um exercício de questionamentos e reflexões inicialmente analisados num viés feminista e queer, mas atualmente revisitados a partir de mais um viés teórico que tem refinado nossa análise para se pensar a produção dos corpos trans: a Teoria Ator-Rede (TAR).

Os corpos dos homens trans são corpos, ao nascerem, designados como corpos de mulher. Essa designação é uma técnica do saber-poder médico e jurídico, em consonância com discursos morais, políticos e religiosos, a partir de uma classificação pautada no dimorfismo sexual, numa analogia direta entre sexo e gênero, que não aceita a possibilidade de outras experiências em corpos já assinalados ao nascerem.

O corpo não é um dado passivo sobre o qual age o biopoder, mas antes a potência mesma que torna possível a incorporação prostética dos gêneros (Preciado, 2011:14). 
Mas como se dá essa incorporação? Os corpos transmasculinos são um devir, um processo em construção desde sempre. Tanto para muitas/os de nós, pesquisadoras/es, quanto para a mídia ou para o público leigo, a "transição" supostamente tem um "ponto de partida", um momento quando a pessoa trans "começa a perceber" sua identidade de gênero como distinta da sua experiência corpórea e afetiva em relação ao sexo que lhe foi designado socialmente. A própria noção de transição é problemática nesses termos, pois pressupõe uma transição entre dois polos: homem/mulher ou masculino/feminino.

Contudo, uma das contribuições dessa pesquisa foi justamente oferecer subsídios para desconstruir esse estereótipo. Parte dos nossos interlocutores nos ensinou que as pessoas trans nem "nascem" com essa percepção, nem "a percebem" em algum momento da vida. Os corpos trans são devires, processos de construção desde sempre. De fato, todos os corpos são. Mas, no caso das pessoas trans, e aqui particularmente no que tange aos corpos transmasculinos, esses processos de contínua construção são performados por um conjunto de técnicas específicas, como a hormonização (uso da testosterona), a mastectomia masculinizadora (retirada das mamas com reconstrução peitoral), a histerectomia (retirada do útero), faixas e binders (para comprimir e esconder as mamas), a musculação etc. No que tange à cirurgia de transgenitalização de corpos transmasculinos, ainda é considerada experimental no Brasil e não se configura entre as prioridades ou principais técnicas acionadas por pessoas transmasculinas. Nas palavras de Latour, o corpo "aprende" à medida em que é afetado pelo mundo. Nesse sentido, o corpo é "adquirido" através de "um empreendimento progressivo que produz simultaneamente um meio sensorial e um mundo sensível" (Latour, 2008:39). Adquirir um corpo é um processo, uma experiência. O corpo é "aquilo que deixa uma trajetória dinâmica através da qual aprendemos a registrar e a ser sensíveis àquilo de que é feito o mundo" (Latour, 2008:39). E aqui podemos acrescentar que o mundo, ao menos numa perspectiva ocidental, é feito de gêneros. Mais especificamente, de dois gêneros opostos 
e excludentes (Scott, 1995). Pensemos, pois, em como o mundo afeta os corpos, produz materialidades e as coloca em movimento. Problematizemos como todas/os nós "performamos" nossos corpos, mais próximas/os ou mais distantes da norma. E aqui estamos falando em performar no sentido atribuído por Annemarie Mol, do inglês enact, que poderia ser traduzido como atuar, efetivar, efetuar. Contudo, usualmente enact tem sido traduzido como "performar" nas traduções brasileiras $e$ portuguesas em TAR, no sentido de que o actante (humano ou não-humano) constrói materialidades e produz "realidades". $\mathrm{Na}$ presente discussão, adotaremos performar e efetuar como sinônimos.

Na primeira parte do artigo, resgataremos o debate de Beto Preciado, um dos principais expoentes da Teoria Queer, para se problematizar o hormônio (no caso a testosterona) como um biocódigo de gênero que possibilita a produção "técnica" do corpo. Na segunda parte, com ênfase na Teoria Ator-rede (TAR), a própria noção de corpo é revisitada à luz da perspectiva de Bruno Latour, a noção de técnica é retomada, o hormônio passa a ser concebido não somente como biocódigo, mas como um ator dentro de uma rede sociotécnica de elementos humanos e não humanos que afeta e efetiva seus corpos, coproduzindo, performando movimentos e realidades vividas para além do que a Medicina define e entende sobre esses corpos. Por fim, $e$ ainda na segunda parte que abrange as contribuições da TAR, com base no debate de Annemarie Mol sobre as políticas ontológicas, vemos um subsídio da Teoria Ator-Rede para problematizarmos a patologização das identidades e repensarmos as políticas públicas para pessoas trans.

\section{Testosterona em rede: materializando corpos queer}

No caso das pessoas trans, a norma já é transgredida num primeiro momento, quando da não identificação subjetiva da pessoa com o gênero que lhe foi designado socialmente. Essa desidentificação (Preciado, 2009) não é disforia, não é 
incongruência, não é patologia. A desidentificação é, ao mesmo tempo, corpórea, psicológica, subjetiva, auto expressiva, relacional e política. Partindo dessa perspectiva, o objetivo deste artigo é pensar quais as técnicas e tecnologias que afetam e efetuam a materialidade desses corpos.

Quando o tema são os homens trans, a questão do hormônio aparece sempre como um tópico de destaque. Há muita especulação em relação aos efeitos supostamente negativos da administração de hormônios por parte das pessoas trans. Nessa direção, entrevistamos a endocrinologista de um respeitado ambulatório trans da Universidade Federal de Uberlândia, que se tornou referência na especialidade. Esclareceu-nos que parte da testosterona se transforma em estrogênio e não prejudica a massa óssea, já que é o estrogênio que a protege. A endocrinologista mencionou ainda um estudo na literatura médica internacional, recém-publicado à época da entrevista, o qual havia acompanhado homens e mulheres trans por dez anos, concluindo que não havia ocorrido aumento de mortalidade ou de efeitos colaterais no caso dos homens trans. Resumidamente, segundo a médica, "tudo depende do tipo de hormônio $e$ do acompanhamento".

Segundo a profissional, a maioria dos homens trans que ela atende "aderem mais ao tratamento", na comparação com as mulheres trans. Isso acontece, na avaliação dela, devido ao grau de satisfação com a terapia. Ao contrário do que diz o senso comum de que a hormonização gera "efeitos mais rápidos" nos homens trans que nas mulheres, a endocrinologista, com base em sua experiência com essa população, afirma que o processo não é necessariamente mais rápido, mas mais satisfatório em termos de autopercepção. Sobre os resultados do acompanhamento, ela nos relatou sucesso na alteração da voz, aumento do clitóris e da libido. Por outro lado, queixas de irritabilidade, nervosismo e dor no clitóris nos primeiros meses também são recorrentes, mas não comprometem à adesão ao tratamento, que seguem com o tratamento apesar das queixas. 
Questionada pela bolsista do projeto sobre as diferenças entre as testosteronas comercializadas no Brasil, explicou-nos, didaticamente, que o Durateston é composto por uma série de sais, o que aumenta a probabilidade de "picos" do hormônio no organismo, mas que já nem estava mais sendo fabricado. Já o Deposteron é apenas um sal, o que pode diminuir a oscilação e os "picos" (e é o mesmo hormônio que vendido no mercado paralelo, que vem do Paraguai com outro nome $)^{2}$. Segundo ela, a testosterona mais recomendada, a Nebido, deveria ser administrada de doze em doze semanas e é considerada "fisiológica", pois mantém o nível de testosterona estável no organismo. Contudo, é de alto custo. A médica mencionou que, pela portaria, deveriam receber o tratamento, mas ficou em dúvida sobre qualquer prescrição específica no documento. Estava fazendo uma referência à Portaria $\mathrm{n}^{\circ}$ 2.803/2013, que "redefine e amplia o Processo Transexualizador no Sistema Único de Saúde (SUS)". Consultando o documento, podemos afirmar que havia uma menção a "hormonioterapia" ou "terapia medicamentosa hormonal", mas sem definição de que tipo de hormônio deveria ser utilizado. Se o documento não menciona, torna-se um elemento complicador para se reivindicar o andrógeno na rede pública.

Além disso, segundo a endocrinologista, ao menos até aquele momento, havia poucos trabalhos científicos comparando os efeitos dos diferentes andrógenos. Mas, com base em sua experiência de atendimento, a médica nos relatou que, do ponto de vista fisiológico, a Nebido era melhor; do ponto de vista da masculinização, era indiferente. As doses começam numa base de 30 em 30 dias e passam a ser ajustadas individualmente. Mas a médica ressaltou que "Tudo tem que ser individualizado" $e$ exemplificou com um de seus pacientes que precisa da administração da testosterona uma vez por mês, enquanto outro a

\footnotetext{
${ }^{2}$ Ver mais sobre essa discussão da testosterona sintética em Vieira e Porto (2019).
} 
necessitava de dez em dez dias para alcançar os mesmos resultados do primeiro.

Essa breve apresentação da entrevista com a profissional teve o objetivo aqui de situar $\mathrm{a} / \mathrm{o}$ leitora $/ \mathrm{r}$ a respeito dos andrógenos disponíveis no mercado e alguns de seus efeitos. Contudo, minha intenção neste artigo não é debater sobre os efeitos colaterais da administração da testosterona, nem mesmo sobre o processo de masculinização. O que nos interessa aqui é entender como os hormônios performam corpos transmasculinos a partir de uma de um processo de "hackeamento" de informações, substâncias e técnicas que se desviam das tecnologias normativas do corpo produzidas politicamente e possibilitam outras materializações e experiências. Lucas ${ }^{3}$, um dos interlocutores de nossa pesquisa em Campinas, ao narrar sobre sua dificuldade inicial em conseguir um atendimento com um a endocrinologista, chegou a ouvir de um médico: "Não atendo esse tipo de gente." Esse "tipo de gente" que se desvia da norma, que ousa transformar seus corpos e suas vidas através de uma apropriação consciente e subjetiva da testosterona e de outras técnicas, numa rede que lhes permite a experimentação e a "aquisição" de um corpo masculino ou masculinizado em alguma medida.

\section{"A hormonização era só o que faltava"}

A pesquisa revelou que a hormonização, apesar da sua importância no processo, não caracteriza seu início. $\mathrm{Na}$ experiência de Lucas, a hormonização era só o que faltava no processo de masculinização, que já havia se iniciado há muito tempo através da apropriação de técnicas do corpo, sobretudo atividades físicas. Em certa medida, poderíamos dizer que ela apenas materializa parcialmente um processo que já está há muito tempo em andamento.

Contestando as formas de controle biopolíticos sobre os corpos, Preciado aponta para as

${ }^{3}$ Nome fictício, inspirado em Lucas Silveira, conhecido homens trans canadense, líder de uma banda de rock. 
nuevas reinvindicaciones que proceden de cuerpos minoritarios y de sus modos de reapropiación de las tecnologías farmacopornográficas de producción de la identidad: demandas de re-definición del cuerpo y de la identidad sexual e invención de formas de 'desobediencia de género' que proceden de los colectivos transgénero y gender-queer, pero también críticas de los dispositivos teológico y médico-jurídicos de asignación de género en la primera infancia... (Preciado, 2009:s/p.).

No texto "Transfeminismo y políticas del género em la era farmacopornográfica" (2009) ${ }^{4}$, o autor nos leva a refletir sobre um diagrama que cartografa as alterações da gramática do feminismo clássico para um feminismo queer e pós-colonial. Dentre outros elementos desse diagrama, gostaria de colocar apenas alguns aqui em evidência para nossa discussão, que seriam mudanças de paradigma entre esses feminismos: da essência para a materialização performativa, da discussão de identidade para a desidentificação, do gênero para o tecnogênero, dos caracteres sexuais secundários para os biocódigos de gênero, do essencialismo ou construtivismo para arquiteturas vivas, da representação para experimentação e mutação.

Numa perspectiva queer, o sexo não é essência, mas materialização performativa, desidentificação com o binarismo sexual e com uma suposta relação de causa e efeito entre sexo, gênero e sexualidade. Os corpos não são representações de uma natureza ou de uma cultura, mas mutações criativas $e$ materialmente possíveis. Nesse contexto, a discussão sobre identidade perde lugar, já que pressupõe uma coesão e uma coerência de si baseadas na estabilidade. Mas a performatividade não é estável, ela é processo, é devir, não produto. Quando Preciado menciona a desidentificação, entendo como um deslocamento da noção ocidental moderna de identidade, como

\footnotetext{
${ }^{4}$ Palestra de Preciado proferida em Roma, em espanhol., transcrita e publicada posteriormente em italiano no livro Le cinque giornate lesbiche in teoria em 2010. Agradecimentos a Thiago Coacci por essas informações.
} 
Butler bem problematiza (2003), ao questionar em que medida a identidade (no sentido filosófico, de características internas, caracterizadas pela continuidade e coerência ao longo do tempo) não seria mais um ideal normativo do que uma descrição da experiência, lembrando-nos que as práticas reguladoras do gênero são as mesmas que controlam as noções culturalmente inteligíveis sobre identidade.

\begin{abstract}
Em outras palavras, a "coerência" e a "continuidade" da "pessoa" não são características lógicas ou analíticas da condição de pessoa, mas, ao contrário, normas de inteligibilidade socialmente instituídas e mantidas (Butler, 2008:38).
\end{abstract}

Se chegamos ao ponto da discussão em que a identidade é socialmente instituída e regulada e que o corpo é coproduzido por um conjunto de técnicas, a ideia da desidentificação é justamente refutar as práticas reguladoras de um ideal normativo, "fazendo dos discursos sobre o sexo e das tecnologias de normalização das identidades sexuais um agente de controle da vida" (Preciado, 2011:11). Para Preciado, a desidentificação diz respeito a uma desontologização dos sujeitos políticos. Não é por acaso que "a teoria queer surge em um momento de reavaliação crítica da política de identidades" (Pino, 2007). Mas então seria então o caso de desconstruir as identidades? Em certa medida, sim, mas sem deixar de considerar a materialidade da rede sociotécnica que coproduz esses corpos. Butler (2000) sugere "um retorno à noção de matéria, não como local ou superfície, mas como um processo de materialização que se estabiliza". Nas palavras de Preciado, "um conjunto de tecnologias do corpo, técnicas farmacológicas e audiovisuais que determinam e definem o alcance das nossas potencialidades somáticas e funcionam como próteses de subjetivação" (Preciado, 2018:127).

Há quem se pergunte sobre a concretude das estratégias políticas queer. A concretude está nos corpos, em novas possibilidades de materialização que escapem das tecnologias 
normativas do corpo, numa espécie de "hackeamento" dessas tecnologias. Mas, para isso, certas tecnologias do corpo $e$ farmacológicas são reapropriadas por esses corpos não-dóceis, como forma de resistência e subversão. Um tipo de "emancipação farmacopornográfica" dos corpos subalternos ocorre ao se apropriarem desses biocódigos produzidos politicamente $e$ coproduzirem novos "tecnogêneros", nos termos de Preciado.

$\mathrm{O}$ autor Paul B. Preciado é um exemplo de como a Teoria Queer pode nos ser importante nessa discussão sobre a materialidade desses corpos trans coproduzidos. No caso de Preciado, estamos levando em conta não apenas a produção teórica do autor, mas também as próprias mutações queer coproduzidas em seu corpo. Em Testo Junkie (2018), Preciado apresenta seu livro como "um protocolo de intoxicação voluntária à base de testosterona sintética a respeito do corpo e dos afetos de B. P." (2018:13). Preciado sugere que "o gênero farmacopornográfico parece ser sintético, maleável, variável, aberto à transformação e imitável, assim como possível de ser tecnicamente produzido e reproduzido" (Preciado, 2018:116).

Descrevendo seu processo, Preciado escreve que "corpos em mutação em todo o planeta, trocam técnicas e saberes. Nessa rede audiovisual, meu rosto é indiferente, meu nome, insignificante. Apenas a estrita relação entre meu corpo e a substância [testosterona] é objeto de culto e vigilância" (Preciado, 2018:22-23). Mas como se dá essa relação entre o corpo e a substância? Repolês (2017), em sua dissertação de mestrado, escreve sobre a experimentação de substâncias e técnicas a partir de sua trajetória e de seus interlocutores:

Muitas vezes essas intervenções podem a curto ou longo prazo trazer efeitos inesperados em nossos corpos. Alguns de nós nos surpreendemos ao longo desses processos com a quantidade de pelos que surgem em lugares inesperados, com a forma que a gordura de nosso corpo é redistribuída, com as transformações de nossos genitais, ou com alterações de odores e texturas de nossos corpos e fluidos corporais, por exemplo. A hormonização pode trazer outras 
mudanças tais como a interrupção do ciclo menstrual, o aumento da libido, mudanças no tom de nossas vozes, alteração do semblante e traços de nossos rostos, o aumento da oleosidade da pele e o aparecimento ou intensificação de acnes e espinhas, aumento de massa muscular e, a longo prazo, a queda de cabelo. Isso não significa que todas essas mudanças irão acontecer com todas as pessoas transmasculinas que se hormonizam, tampouco que as mudanças ocorrem da mesma forma ou com a mesma temporalidade, e podemos também experimentar outras alterações não consideradas aqui (Repolês, 2017:72-73).

Quais são os elementos que colocam esses corpos em movimento e os efetuam, fazendo com que sejam reconhecidos e que "existam"? A partir do próximo item, tentaremos responder parcialmente, de forma localizada, a partir de subsídios da reflexão de Bruno Latour sobre o corpo.

\section{Revisitando a noção de corpo: contribuições da teoria ator-rede}

\section{Como bem define Latour}

Se o contrário de ser um corpo é morrer, não podemos pretender ter uma vida separados do corpo, muito menos uma vida depois da vida, ou uma vida do espírito: ou se tem um corpo, se é um corpo; ou está-se morto, é-se cadáver, um número numa macabra contagem de corpos. É esta a consequência directa do argumento de Vinciane Despret, inspirado nas ideias de William James sobre as emoções: ter um corpo é aprender a ser afectado, ou seja, «efectuado», movido, posto em movimento por outras entidades, humanas ou não-humanas. Quem não se envolve nesta aprendizagem fica insensível, mudo, morto (Latour, 2008:39).

Latour (2008) propõe então pensarmos o corpo como uma interface que precisa se deixar afetar/efetuar por outros muitos elementos para se tornar descritível. O corpo, portanto, não é algo a ser 
definido, mas a ser sensibilizado para ser afetado/efetuado por esses outros elementos "de que é feito o mundo" (Latour, 2008:39), de forma dinâmica, progressiva e ambígua. "Concentrando-nos no corpo, somos imediatamente - ou antes, mediatamente conduzidos àquilo de que o corpo se tomou consciente" (Latour, 2008:39). Não se trata se uma discussão entre dualismo e holismo, mas de "devolver ao corpo todos os equipamentos materiais que o tornam sensível às diferenças" (Latour, 2008:40). Nesse sentido, ao ser afetado e tornar-se consciente do que o afeta e o efetua, o corpo é adquirido e a dualidade mente-corpo perde sentido, pois se caracterizava até então como produto da falta dessa definição de corpo para além de um modelo pautado na quase sinonimidade entre corpo e sujeito, constituindo uma essência (interna) que se opõe e não depende do mundo (externo) para se constituir. A linguagem seria mediadora entre esse corpo-sujeito $e$ o mundo, numa lógica em que a aprendizagem por parte do corpo não teria lugar. Afetar-se não seria necessário, porque a essência seria definida aprioristicamente.

Em relação aos corpos transmasculinos, a aquisição de caracteres masculinos através da testosterona, aliada à mamoplastia, além de aumentarem a "passabilidade" (e aceitação) nas relações sociais, facilitam o acesso aos hormônios, geralmente negado pelos médicos diante de homens trans que não correspondam ao imaginário ocidental da masculinidade (aqui será citado artigo em coautoria sobre esse debate). Nesse sentido, podemos dizer que, do ponto de vista médico, a masculinidade está associada à materialidade e à representação de uma essência, enquanto os corpos dos homens trans, sensiveis às suas diferenças, "aprendem", deixam-se afetar por outros elementos do mundo. Os corpos trans tornam-se conscientes através de uma rede sociotécnica de elementos humanos e nãohumanos que os afeta e efetua, coproduzindo movimentos $e$ realidades vividas para além do que a Medicina define e entende sobre esses corpos. Mas de que forma os corpos trans tornam-se conscientes, utilizando esse termo a partir de Latour? 
Em artigos anteriores (aqui faremos referência aos artigos), afirmamos que "para se obter essa aparência 'mais masculina', a hormonioterapia é tida como fundamental. Nesse contexto, bem sabemos o quanto as pessoas trans se utilizam do próprio discurso patologizante do sistema para que suas demandas se tornem 'inteligíveis' e urgentes para os/as profissionais da saúde. Esse exercício das pessoas trans é, por vezes, compreendido como uma apropriação autônoma da norma, em outras vezes é lido como um comportamento que reproduz a norma.

Contudo, nos termos de Latour, podemos analisar a questão a partir de outra perspectiva, de "corpos que aprendem a ser afectados por diferenças que anteriormente não podiam registrar, através da mediação de um arranjo artificial" (Latour, 2008:40, grifos nossos). E aqui a "artificialidade" aqui acionada por Latour nos remete ao mito do ciborgue de Donna Haraway (2000), evocando que a tecnologia "embaraça" as fronteiras que conhecíamos como verdadeiras, como natureza/cultura, orgânico/artificial.

Nesse sentido, meu argumento é que, quando as pessoas trans acionam um discurso normativo para torná-lo convincente, não se trata nem de uma apropriação autônoma nem de uma simples reprodução. De fato, o que estou sugerindo é que elas já passaram por um processo em que seus corpos já foram afetados/efetuados por técnicas e elementos que não compõem $e$ que excedem o modelo médico sobre a transexualidade, pautado nas dicotomias natureza/cultura e natural/artificial. Uma vez que seus corpos já foram afetados pelas técnicas, uma masculinidade outra é coproduzida, uma materialização distinta da masculinidade-essência-aparência-universal da perspectiva médica. Nas palavras de Repolês (2017),

É importante ressaltarmos que não há uma lista determinada de intervenções corporais que devemos cumprir para que sejamos reconhecidos enquanto trans ou para que nossa auto identificação seja validada. Estas mudanças não precisam ser realizadas de forma coercitiva ou compulsória, mas sim como artifícios para que nos 
adequemos às nossas próprias necessidades e desejos a respeito de nossa autoimagem (Repolês, 2017:73).

Segundo Latour, "quanto mais contraste se acrescenta, a mais diferenças e mediações se fica sensível. [...] Quanto mais controvérsias articulamos, mais vasto se torna o mundo." (Latour, 2008:44-45). Nesse sentido, minha perspectiva é que as pessoas trans, por viverem nas controvérsias do próprio sistema de saúde, "hackeiam" informações $e$ técnicas e materializam o gênero a partir da articulação dessas controvérsias. Segundo Latour, a maior vantagem do termo "articulação" é a sua capacidade para trazer a lume os componentes artificiais $e$ materiais que permitem progressivamente adquirir um corpo (Latour, 2008:43). Ou seja, a articulação nega qualquer determinismo a priori, já que é em rede que o corpo é afetado e se efetua, colocado em movimento e "adquirido". Na mesma direção, Law \& Mol também problematizam como a materialidade e a socialidade são coproduzidas:

Talvez a associação não seja apenas uma questão para seres sociais, mas também está relacionada a materiais. Talvez, então, quando olhamos para o social, estamos também olhando para a produção de materialidade. $\mathrm{E}$ quando olhamos para os materiais, estamos testemunhando a produção do social (Law \& Mol, 1995:274, tradução livre).

\section{Políticas, corpos e "fatos": sobre a despatologização $e$ as políticas públicas de saúde}

Quando pensamos em performar, efetuar um corpo, estamos sugerindo a sua "aquisição", quando ele "torna-se real" na relação entre a materialidade e a socialidade, como vimos acima. Mas o que seria o "real"? Mol evoca o "real" no seu sentido ontológico, das "condições de possibilidade com que vivemos" (Mol, 2007:21). Segundo Mol, a tradicional divisão entre o real e o político, assim como entre natureza e cultura, já foi derrubada pela teoria ator-rede e por outras teorias. Partimos, 
assim, do pressuposto de que reconhecemos as diferenças, a pluralidade e a falácia dos binarismos. Mas Mol nos coloca uma pergunta muito relevante: e em outros domínios "na vida tal como é vivida em diferentes locais e situações: nas políticas estatais, nos movimentos sociais, na formação tecnocientífica"? (Mol, 2007:3). Porque a realidade não precede as práticas, mas é modelada por elas (Mol, 2007).

Mol argumenta que reconhecer perspectivas distintas $e$ plurais não resolve o problema político. Multiplicam-se os olhares, mas não uma única suposta realidade estável $e$ intocada. A realidade é histórica, não natural. Alega-se que outras possibilidades reais poderiam ter sido construídas, mas de fato não foram, não existiram e não existem. Para repensar então a questão, Mol propõe que, para além das noções de perspectiva e construção, pensemos também em intervenção e performance, no sentido de que "uma realidade é feita e performada" (Mol, 2007:6, grifos nossos), mais que simplesmente observada. Porque apenas observar implicaria numa realidade pronta $e$ inerte, mesmo que observada por prismas diferentes. $\mathrm{E}$ assim também temos pensado o sexo e o gênero. Mas, se reconhecemos que a realidade é feita e performada, a intervenção é pressuposta.

Os objetos (e as pessoas) não existem a priori, são versões diferentes, que intervêm e que ajudam a performar a tal realidade, versões que coexistem e não são necessariamente excludentes. Então como pensar políticas públicas para pessoas trans, se entendemos que há uma multiplicidade de possibilidades de experimentações e materializações trans?

Aqui nos vemos, via de regra, divididas/os entre um modelo de mercado e um modelo Estatal que assume o controle da saúde da população. Quais os efeitos dessas intervenções? E quais as opções em jogo? Existem escolhas de fato? Essas são questões da autora que também deveriam orientar a problematização das políticas públicas para pessoas trans.

Uma decisão ganha ares de "fato", num processo em que os lugares de produção desses fatos não aparecem. Na citação 
abaixo, Mol ilustra bem esse processo de estabilização de "fatos", de "verdades":

Se a medicina performasse todos os desvios de formas individualizadas, muitas das "inegáveis" diferenças biológicas entre os sexos pura e simplesmente desapareceriam (Mol, 2007:14).

O ponto no qual quero chegar é que essas categorias que se pretendem homogêneas, para se estabilizarem enquanto "fatos", escondem as controvérsias das políticas ontológicas, que não são nem homogêneas, nem individuais, pois são produtos de "decisão" entre diferentes versões em disputa, fabricadas através da intervenção de agentes humanos e não-humanos. Mol (2007) ilustra com o exemplo das práticas em epidemiologia, nas quais as classificações performam "mulher" como uma categoria biológica.

A questão se complexifica ainda mais quando a medicina $e$ os laboratórios se utilizam desses supostos "fatos" para definir entre o normal e o desviante/patológico, já produzindo um diagnóstico a priori. E daí temos todo o controverso debate sobre despatologização e desmedicalização. Despatologizar seria sinônimo de desmedicalizar ou desassistir? (Almeida, 2013; Prado, 2018).

Butler (2009), ao discorrer sobre algumas controvérsias sobre o diagnóstico médico para pessoas trans nos Estados Unidos, oferece-nos subsídios para refletirmos sobre as controvérsias da despatologização no Brasil. Não muito diferente do Brasil, ela menciona que o diagnóstico pode se tornar um instrumento de patologização, ao mesmo tempo que se apresenta, do ponto de vista de uma parcela das pessoas trans, como uma forma de acesso aos serviços de saúde.

Estamos de acordo com Butler quando ela menciona que "(o) diagnóstico reforça formas de avaliação psicológica que pressupõem que a pessoa diagnosticada é afetada por forças que ela não entende" (Butler, 2009:97). Deriva dessa lógica que, se a pessoa não entende, é o saber-poder da medicina que 
determinará seu tempo de espera para uma possibilidade de transição (Vieira, 2015; Almeida, 2018; Braz, 2019a; Braz, 2019b). A patologização, apesar de favorecer o acesso aos serviços de saúde $e$ ao processo transexualizador, atua no nível simbólico a partir de um binarismo ocidental pautado nas diferenças sexuais entre macho e fêmea, a partir do referencial do sexo. A patologização reduz a experiência queer a uma suposta verdade biológica $e$ busca adequar os corpos trans ao modelo binário heterossexual.

Contudo, assim como o diagnóstico mencionado por Butler nos Estados Unidos, no Brasil também há controvérsias em relação à questão, sobretudo no que se refere ao Manual Diagnóstico e Estatístico de Transtornos Mentais (DSM) e à Classificação Estatística Internacional de Doenças e Problemas Relacionados com a Saúde (CID).

Bento e Pelúcio também problematizam as classificações do DSM, o qual, apesar de ser um material de referência psiquiátrica, "consegue se materializar em políticas do corpo nos programas de identidade de gênero e em políticas de Estado, uma vez que compartilha com os outros saberes as mesmas bases fundacionais definidoras do gênero" (Bento e Pelúcio, 2012:575).

Durante a pesquisa, um de nossos interlocutores, de expressivo lugar na militância brasileira, relatou-nos sobre a importância de banir o diagnóstico, mas garantir o acesso à saúde. Nesse processo, segundo ele, não haveria problema se a transexualidade continuasse tendo um número $e$ um nome na Classificação Estatística Internacional de Doenças e Problemas Relacionados com a Saúde. Na percepção de nosso interlocutor, tratava-se apenas de uma questão burocrática. Aqui nos deparamos com uma outra controvérsia: desdiagnosticar pode ser uma das formas de despatologizar. Mas seria possível desdiagnosticar mantendo a transexualidade como doença no rol da Classificação Internacional? Seria a CID apenas uma técnica da burocracia ou mais um biocódigo, nos termos de Preciado? A CID também não teria a força de ter suas classificações referenciadas $e$ materializadas nas políticas públicas, como no caso da DSM citado por Bento e Pelúcio (2012)? 
Em 2013, uma polêmica instaurou-se entre transmasculinos no Brasil, no que se refere ao PL 72/07 do Deputado Luciano Zica. Para entendermos essa problemática, é preciso que esclareçamos que, na época, no Brasil, havia duas organizações políticas: A Associação Brasileira de Homens Trans (ABHT) e o recém (à época) fundado Instituto Brasileiro de Transmasculinidade (IBRAT). Como bem sabemos, os "rachas" são bastante comuns dentro dos movimentos sociais devido a posicionamentos políticos divergentes, ainda que dentro de uma mesma população. Esse movimento foi muito bem explicado por E. MacRae em $A$ Construção da Igualdade (1983), sobre o movimento LGBT no Brasil. Nesse sentido, o IBRAT é um grupo dissidente da ABHT e, apesar de uma luta por causas comuns, havia percepções diferenciadas, versões em disputa quanto às formas dessa luta. A polêmica do PL 72/07 é um exemplo. A ABHT se posicionou radicalmente contra, justamente por manter a exigência do laudo. O PLC alteraria o art. 58 da lei 6015/73 - o nome poderia ser alterado em casos de transexualidade, sem o pré-requisito da cirurgia, mas sob a condição de apresentação de laudo médico. Contudo, essa interpretação não foi consensual. Apesar de adesão de várias entidades e organizações, muitos homens trans se manifestaram a favor do PL como um "começo" para as mudanças, a despeito dos problemas que apresenta na sua redação.

Em artigo publicado na época por Berenice Bento (2013), a autora aponta para alguns problemas do PL: a restrição às pessoas transexuais, excluindo travestis, crossdressers e outros que não se identificassem como transexuais; a patologização que era referendada; a manutenção de um longo processo que já se arrastava por anos; a normatização médica e jurídica:

Já de posse do laudo, a pessoa enfrentará novas filas e novas rotinas, agora na Justiça, para demandar a mudança do nome e do sexo nos documentos. Na Justiça, terá que se preparar para longo e caro processo. Terá que torcer para que o processo caia na mão de um magistrado mais 
liberal, pois nada o obrigará, nos termos da lei, a autorizar as mudanças. Ou seja, são anos e anos até conseguir um direito básico: ser reconhecido legalmente com a mesma identidade social com a qual vive. Essa realidade, que vem sendo questionada como desumanizadora, é definida como norma pelo PL 72/2007 (Bento, 2013, s/p.).

Enquanto o PL 72/2007 e o PL 5002/2013 (Lei de Identidade de Gênero, também conhecida como Lei João Nery) continuavam em discussão, em 19 de novembro de 2013 foi publicada a Portaria $\mathrm{n}^{\circ}$ 2.803, que revisava o Processo Transexualizador no âmbito do Sistema Único de Saúde (SUS). O PL 72/07 foi arquivado em 2014; a Lei João Nery, em 2019.

A cirurgia de transgenitalização para pessoas transmasculinas é reconhecida desde 2010, mas desde então permanece o seu caráter experimental, e esse ponto não foi alterado pela Portaria de 2013. A partir da Portaria $n^{\circ} 2803 / 2013$, a mastectomia, a histerectomia e a hormonioterapia passaram a se configurar como possibilidades no SUS ou planos de saúde particulares, desde que os homens trans consigam se desviar das técnicas de controle e regulações médicas e burocráticas. Cabe ressaltar que os termos adotados na Portaria não condizem com as reivindicações de ativistas trans. O documento faz referência à "transformação do fenótipo masculino para feminino e do feminino para o masculino" e não há nenhuma referência à transmasculinidade. Em 2019 foi publicada a Resolução $n^{\circ}$ 2.265/2019 do Conselho Federal de Medicina, que "(d)ispõe sobre o cuidado específico à pessoa com incongruência de gênero ou transgênero e revoga a Resolução CFM n ${ }^{\circ}$ 1.955/2010." Só então o termo transgênero figura num documento oficial sobre o tema, mas ainda assim traz a problemática noção de "incongruência de gênero" da CID-11, uma vez que a transexualidade foi retirada da categoria de "transtornos mentais" para integrar o de "condições relacionadas à saúde sexual", mas o seu potencial patologizante ainda é alvo de críticas (Val, Prais e Souza, 2021, no prelo). 
Desdiagnosticar pode ser um primeiro passo para a despatologização. Mas como despatologizar sem desmedicalizar ou desassistir? Segundo Almeida e Murta (2013:399), no Brasil existe uma "ideia da vivência transexual como entidade nosológica" ${ }^{5}$. Isso significa que, deslocada da CID, a assistência à saúde das pessoas trans precisaria ser totalmente repensada.

diante da possível retirada do "transexualismo" do CID ou o seu não uso pelo SUS, como garantir/ampliar o acesso de pessoas trans ao sistema, se todo ele opera majoritariamente pela lógica da doença e do transtorno $e$, consequentemente, da correção dos corpos ao padrão que se definiu como normal?

Ainda que reconheçamos a importância da normatização, há algumas pistas que podemos perseguir para compreender como vem se dando efetivamente a patologização da transexualidade no SUS e, mais ainda, se ambicionamos superá-la na direção de modelos assistenciais mais satisfatórios (Almeida e Murta, 2013:400).

Se, para os autores, despatologizar sem uma perspectiva de atenção integral à saúde das pessoas trans seria um retrocesso, podemos concluir, por ora, que a despatologização é necessária, mas implica numa série de controvérsias ainda pouco problematizadas. Desdiagnosticar pode ser uma das formas de despatologizar, de se desviar das tecnologias normativas do corpo, mas sem desassistir ou descuidar (Prado, 2018). É importante que essas diferenças sejam destacadas para que a luta pela despatologização seja travada com vistas à diversidade de experimentações e materialidades dos corpos trans, sem se tornar um Cavalo de Tróia.

\footnotetext{
${ }^{5}$ Segundo o dicionário médico, a definição de "entidade nosológica" é "doença individualizada, com características e propriedades inerentes à patologia." (https://www.dicionáriomédico.com/entidade_nosol\%c3\%b3gica.html).
} 


\section{Conclusão}

As controvérsias são evidentes e parecem dificultar nossa capacidade de pensar em outras políticas ontológicas, mas temos que começar a pensar seriamente sobre isso. Vivendo (n)as controvérsias do sistema de saúde, as pessoas trans articulam técnicas, estratégias e discursos que performam seus corpos, suas subjetividades e seus afetos. Materializam corpos não reconhecidos pelo sistema em sua plenitude humana, política $e$ social. Corpos que são expulsos de consultórios, de suas famílias, de escolas, do mercado de trabalho e da própria condição humana. Apesar da precaridade de suas vidas (Butler, 2011, 2018), cada vez mais a multidão queer (Preciado, 2011) tem ocupado as ruas e os espaços sociais que sempre lhe foram negados. Para os corpos transmasculinos, a testosterona pode ser o começo, pode ser o meio, pode ser o fim. Numa rede, não há linearidade no processo, não há uma "ordem", "fatos" ou "verdades" que devam pautar a produção dos corpos trans. Alguns fatos e verdades "venceram" temporariamente disputas entre diferentes versões dos discursos médicos, sociais, políticos e religiosos.

Esses supostos fatos $e$ verdades estão estabilizados $e$ procuram ditar suas normas, mas o tecnogênero nega a homogeneidade, a padronização, a patologização. Além disso, não podemos jamais perder de vista a interseccionalidade de gênero, raça, classe e sexualidade para refletirmos sobre as experiências e possibilidades de materialização dos corpos trans, sobre seu acesso às tecnologias de produção do corpo e do gênero.

Os corpos transmasculinos são muitos e são únicos. Cada pessoa trans "hackeia" e se apropria de um conjunto de técnicas (dentro daquelas que lhe forem acessíveis na rede), de forma única, a fim de "fazer a sua realidade" e "adquirir um corpo" no qual ela/e se reconheça. 


\section{Referências bibliográficas}

ALMEIDA, Anderson Santos. Vidas em espera: uma etnografia sobre a experiência do tempo no processo transexualizador. 2018. Dissertação (Mestrado em Programa de Pós-Graduação em Antropologia Social) - Universidade Federal de Goiás, 2018.

ALMEIDA, Guilherme. "Homens trans": novos matizes na aquarela das masculinidades? Revista Estudos Feministas, Florianópolis, v. 20, n. 2, pp.513-523, maio 2012. ISSN 1806-9584 [https://periodicos.ufsc.br/index.php/ref/article/view/S0104-

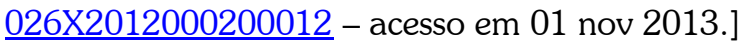

ALMEIDA, Guilherme; MURTA, Daniela. Reflexões sobre a possibilidade de despatologização da transexualidade e a necessidade da assistência integral à saúde de transexuais no Brasil. Sexualidad, Salud \& Sociedad, Rio de Janeiro, n. 14, volume 2, 2013, pp.380407 [http://dx.doi.org/10.1590/S1984-64872013000200017 - acesso em 01 set 2019]

ÁVILA, Simone. Transmasculinidades: a emergência de novas identidades políticas e sociais. Rio de Janeiro, Ed. Multifoco, 2015.

ÁVILA, Simone. FTM, transhomem, homem trans, trans, homem: A emergência de transmasculinidades no Brasil contemporâneo. Tese (Doutorado em Ciências Humanas) - Programa de Pós-Graduação Interdisciplinar em Ciências Humanas da Universidade Federal de Santa Catarina, Florianópolis, 2014.

BENTO, Berenice. Um Cavalo de Troia Chamado PL 72-2007. Correio Braziliense,

$22 / 12 / 2013$ [http://www.clam.org.br/destaque/conteudo.asp?.cod=11380 - acesso em 05 set 2019].

BENTO, Berenice; PELUCIO, Larissa. Despatologização do gênero: a politização das identidades abjetas. Revista de Estudos Feministas, v. 20, n.2, agosto 2012, [http://www.scielo.br/scielo.php?script $=$ sci_arttext\&pid $=$ S0104026X2012000200017\&lng $=$ en\&nrm $=$ isso - acesso em 20 jun 2020].

BRASIL. Ministério da Saúde. Portaria $n^{\circ}$ 2803, de 19 de dezembro de 2013. Redefine e amplia o Processo Transexualizador no Sistema 
Único de Saúde - SUS. Diário Oficial União. 19 dez 2013; Seção 1 [http://bvsms.saude.gov.br/bvs/saudelegis/gm/2013/prt2803_19_11_2 013.html - acesso em 06 set 2019].

BRASIL. Ministério da Saúde. Portaria no 807, de 21 de março de 2017. Redefine e amplia o Processo Transexualizador no Sistema Único de Saúde - SUS. Diário Oficial União. 22 mar 2017; Seção 1 [http://pesquisa.in.gov.br/imprensa/isp/visualiza/index.jsp?data $=22 / 03$ 2017\&jornal =1\&pagina $=69 \&$ totalArquivos $=160$ - acesso em 06 set 2019].

BRAZ, Camilo. ?Acá yo soy un pibe normal? Narrativas sobre la espera y el acceso a derechos entre varones trans en Argentina. Sexualidad, Salud y Sociedade, v. 31, 2019a, pp.119-138 [http://www.scielo.br/scielo.php?script $=$ sci_arttext\&pid $=$ S198464872019000100119\&lng $=$ en\&nrm $=$ iso - acesso em 22 jun 2020.]

$\mathrm{BRAZ}$, Camilo. Vidas que esperam? Itinerários do acesso a serviços de saúde para homens trans no Brasil e na Argentina. Cadernos de Saúde Pública, v. 35, 2019b, pp.1-11 [http://www.scielo.br/scielo.php?script $=$ sci_arttext\&pid=S0102311X2019000400503\&lng =en\&nrm $=$ isso - acesso em 23 jun 2020]

BRAZ, Camilo; SOUZA, Érica Renata de. Hombres trans y salud pública en Brasil - miradas antropológicas sobre nuevos sujetos políticos, reivindicaciones y desafíos In: GIL, C. G. et al. (ed.) Nuevas Cartografias de la Sexualidad. Granada, Espanha, Editorial Universidad de Granada, 2020, pp.467-476.

BRAZ, Camilo, SOUZA, Érica Renata de. Transmasculinidades, transformações corporais e saúde: algumas reflexões antropológicas. In: CAETANO, M.; SILVA Jr., P. M. De guri a cabra macho: masculinidades no Brasil. Rio de Janeiro, Lamparina, 2018, pp.2842.

BRAZ, Camilo; SOUZA, Érica Renata de. A emergência de homens trans como sujeitos de direito no Brasil contemporâneo - demandas, avanços e retrocessos. Anais do $40^{\circ}$ Encontro Anual da Anpocs. Caxambu, ANPOCS, 2016 [http://www.anpocs.org/index.php/papers40-encontro/st-10/st30-3 - acesso em 02 ago 2019].

BUTLER, Judith. Corpos em aliança e a política das ruas. Rio de Janeiro, Civilização Brasileira, 2018. 
BUTLER, Judith. Vida Precária. Contemporânea - Revista de Sociologia da UFSCar, São Carlos, n.1 (Dossiê Diferenças e (Des)igualdades), Jan-Jun 2011 , pp.13-33. [http://www.contemporanea.ufscar.br/index.php/contemporanea/articl e/view/18 a acesso em 31 ago 2019].

BUTLER, Judith. Desdiagnosticando o gênero. Physis Revista de Saúde Coletiva, Rio de Janeiro, 19 [1], 2009, pp.95-126. [http://dx.doi.org/10.1590/S0103-73312009000100006 - acesso em 03 set 2019].

BUTLER, Judith. Problemas de gênero: feminismo e subversão da identidade. Rio de Janeiro: Editora Civilização Brasileira, 2003.

BUTLER, Judith. Corpos que pesam: sobre os limites discursivos do sexo. In: LOURO, G. L. (org.). O corpo educado: pedagogias da sexualidade. Belo Horizonte, Autêntica, 2000, pp.151-172.

COLLING, Leandro. Impactos e/ou sintomas dos estudos queer no movimento LGBT do Brasil. In: GREEN, J. et al. (org.). História do Movimento LGBT no Brasil. São Paulo, Alameda, 2018, pp.515-534.

CONSELHO FEDERAL DE MEDICINA. Resolução nº 2.265 de 20 de setembro de 2019. Diário Oficial da União. Publicado em: 09/01/2020, edição 6, seção: 1, p. 96. Dispõe sobre o cuidado específico à pessoa com incongruência de gênero ou transgênero $e$ revoga a Resolução CFM $n^{\circ}$ 1.955/2010. [http://www.in.gov.br/en/web/dou/-/resolucao-n-2.265-de-20-desetembro-de-2019-237203294. Acesso em 01/07/2020].

HARAWAY, Donna. Manifesto ciborgue: ciência, tecnologia e feminismosocialista no final do século XX. In: Tadeu, Tomaz (org.) Antropologia do ciborgue: as vertigens do pós-humano. Belo Horizonte, Autêntica, 2009, pp.33-118.

LATOUR, Bruno. Como falar do corpo? A dimensão normativa dos estudos sobre a ciência. In: NUNES, J. A., ROQUE, R. (org.). Objetos impuros: experiências de estudos sobre a ciência. Porto, Edições Afrontamento, 2008, pp.39-61 [http://www.brunolatour.fr/sites/default/files/downloads/77-BODY-NORMATIVEPOR.pdf - acesso em 15 ago 2019].

LAW, John, Mol, Annemarie. Notes on materiality and sociality. The Sociological Review, 43, 1995, pp.271-297. 
MAUSS, Marcel. As técnicas do corpo. Sociologia e Antropologia. São Paulo, Cosac Naify, 2003 [1934], pp.399-419.

MOL, Annemarie. Política ontológica: algumas ideias e várias perguntas. In: NUNES, J. A., ROQUE, R. (org.) Objetos impuros: experiências de estudos sobre a ciência. Porto, Edições Afrontamento, 2007, versão do prelo [https://grupoteccc.files.wordpress.com/2011/07/4-politicasontolc3b3gicas.pdf - acesso em 01 ago 2019].

OLIVEIRA, André L. G. "Somos quem podemos ser": os homens (trans) brasileiros e o discurso pela (des)patologização da transexualidade. Dissertação (Mestrado em Ciências Sociais) - Universidade Federal do Rio Grande do Norte. Natal, RN, 2015.

OLIVEIRA, André L. G. "Os homens transexuais brasileiros e o discurso pela des(patologização) da transexualidade" In: JESUS, Jaqueline Gomes de (org.). Transfeminismo: teorias \& práticas. Rio de Janeiro, Editora Metanoia, 2014.

PEREIRA, Pedro P. G. Queer decolonial: quando as teorias viajam. Contemporânea, v.5, n2, jul.-dez. 2015, pp.411-437 [http://www.contemporanea.ufscar.br/index.php/contemporanea/articl e/view/340 - acesso em 01 jul 2019].

PEREIRA, Pedro Paulo G. Queer nos trópicos. Contemporânea, v.2, n.2, jul./dez. 2012 , pp.371-394, [http://www.contemporanea.ufscar.br/index.php/contemporanea/articl e/view/88/53 - acesso em 04 jul 2019].

PINO, Nádia. A teoria queer e os intersex: experiências invisíveis de corpos des-feitos. cadernos pagu (28), jun 2007, pp.149-174 [http://www.scielo.br/scielo.php?script=sci_arttext\&pid=S0104$83332007000100008 \& \operatorname{lng}=e n \& n r m=$ isso - acesso em 04 abr 2013].

PRADO, Marco Aurélio M. Ambulare. Belo Horizonte, PPGCom-UFMG, 2018.

PRECIADO, Paul B. Testo Junkie: sexo, drogas e biopolitica na era farmacopornografica. São Paulo, N-1 Edições, 2018.

PRECIADO, Paul B. Multidóes queer. notas para uma política dos "anormais". Revista Estudos Feministas, Florianópolis, v. 19, n. 1, Apr. 2011, pp.11-20 [http://dx.doi.org/10.1590/S0104026X2011000100002 - acesso em 15 ago 2019]. 
PRECIADO, Paul B. Transfeminismo y micropolíticas del género en la era farmacopornográfica", maio 2009 [http://artenuevo.blogspot.com/2009/05/transfeminismo-y-micropoliticasdel.html - acesso em 01 ago 2019].

REPOLÊS, Sofi G. Recalculando rotas: uma etnografia sobre trânsitos de corpos, afetos e sexualidades em vivências transmasculinas. Dissertação (Mestrado em Antropologia) - Universidade Federal de Minas Gerais, Belo Horizonte, 2017.

SCOTT, Joan W. Gênero: uma categoria útil de análise histórica. Educação \& Realidade, 20 (2), jul.-dez. 1995, pp.71-99 [https://seer.ufrgs.br/educacaoerealidade/article/view/71721/40667 acesso em 01 mai 2019].

SOUZA, Érica Renata de; BRAZ, C. Políticas de saúde para homens trans no Brasil: contribuições antropológicas para um debate necessário. In: Val, A. C. et. al. (org.). Multiplicando os gêneros nas práticas em saúde. Ouro Preto, MG, Editora UFOP, 2016 [http://www.repositorio.ufop.br/handle/123456789/7712 - acesso em 16 ago 2019].

SOUZA, Érica Renata de et al. Transexualidades e saúde no Brasil: entre a invisibilidade e a demanda por políticas públicas para homens trans. 199p. Relatório Técnico - Chamada MCTI/CNPq/SPM-PR/MDA N ${ }^{\circ}$ 32/2012. Faculdade de Filosofia e Ciências Humanas, Universidade Federal de Minas Gerais, Belo Horizonte, 2015.

SOUZA, Érica Renata de; PRADO, Marco Aurélio M. Transexualidades e saúde no Brasil: entre a invisibilidade e a demanda por políticas públicas para homens trans. Trabalho apresentado na Queering Paradigms - Fifth International Conference: Queering narratives of modernity, Quito, FLACSO/Equador, 20-22 fev., 2014a. Não publicado.

SOUZA, Érica Renata de; PRADO, Marco Aurélio M. E a fila não anda: questões sobre transexualidade masculina e saúde, 2014, Rio Grande, RS. In: Anais do VII Congresso Internacional de Estudos sobre a Diversidade Sexual e de Gênero da Associação Brasileira de Estudos da Homocultura. Rio Grande, FURG, 2014b [http://abehcongresso2014.com.br/anais - acesso em 15 ago 2015]. 
VAL, Alexandre Costa; PRAIS, Hugo Alejandro C.; SOUZA, Érica Renata de. Incongruências classificatórias: uma análise dos discursos sobre as propostas da CID 11 em relação às experiências trans. cadernos pagu, 2021, no prelo.

VIEIRA, Cleiton. Viver e esperar viver. corpo e identidade na transição de gênero de homens trans. Dissertação (Mestrado em Antropologia Social) - Centro de Ciências Humanas, Letras e Artes, Universidade Federal do Rio Grande do Norte, Natal, 2015.

VIEIRA, Cleiton; PORTO, Rozeli Maria. "Fazer emergir o masculino": noções de "terapia" e patologização na hormonização de homens trans. cadernos pagu (55), 2019 [http://www.scielo.br/scielo.php?script=sci_arttext\&pid =S010483332019000100505\&lng=en\&nrm=iso. Acesso em 29 jun 2020]. 